pausal, women with disordered endocrine function. The disease models which have been most extensively investigated are those of athletic amenorrhoea and anorexia nervosa. Athletic or exercise induced amenorrhoea is a type of hypogonadotrophic hypogonadism that characteristically affects women engaged in intensive long distance running. In this setting decreases in serum oestradiol and luteal phase progesterone concentrations seem associated with an accelerated loss of trabecular bone, despite the increased mechanical loading of the skeleton. ${ }^{7}$ Milder disturbances of ovulation or cycle length in female athletes are also associated with decreased spinal bone mineral density. ${ }^{8}$ Furthermore, amenorrhoea from other causes-for example, hyperprolactinaemia-has been shown to predispose to progressive spinal osteopenia. ${ }^{9}$ If untreated, hyperprolactinaemic women with amenorrhoea have vertebral bone mass values almost one fifth less than those expected for their age. Although bone loss in the disorder is related to menstrual status, one study has reported that changes in spinal bone mass among hyperprolactinaemic women do not correlate with oestrogen status, suggesting that prolactin may have a direct effect on bone cells or calcium absorption. ${ }^{10}$ The extent to which restoration of menstrual cycles in amenorrhoeic women restores bone mass to normal is uncertain.

Anorexia nervosa provides an even more graphic example of disturbed bone metabolism in premenopausal women. Oestrogen deficiency, malnutrition, and glucocorticoid excess are associated with anorexia nervosa, and all of these may contribute to rapid cortical and trabecular bone loss and fracture. In one longitudinal study of the disorder weight gain, resumption of menstrual function, calcium supplementation, and exercise were not associated with appreciable restoration of skeletal mass over two years, ${ }^{11}$ although a cross sectional study has suggested that bone mass might return to normal after five to 10 years.
These studies suggest that oestrogen status, exercise, and calcium nutrition are the most important, modifiable contributors to peak bone mass. The findings present a challenge to both clinician and epidemiologist. For the clinician clear therapeutic guidelines for the restoration of bone mass in certain readily identifiable disease states are urgently required. For the epidemiologist the design and evaluation of population wide strategies to improve skeletal accretion in childhood and adolescence become a priority.

CYRUS COOPER

MRC Environmental Epidemiology Unit, MRC clinical scientist

University of Southampton,

Southampton General Hospital,

Southampton SO9 $4 \mathrm{XY}$

RICHARD EASTELI Senior lecturer

Clinical Sciences Centre,

Northern General Hospital,

Sheffield S5 7AU

1 Eastell R, Riggs BL. Endocrinology and aging: calcium homeostasis and osteoporosis. Endocrinol Metab Clin Norh Am 1987;16:829-42.

2 Krall EA, Dawson-Hughes B. Heritable and lifestyle determinants of bone mineral density. $\mathcal{F}$ Bone Miner Res 1993;8:1-10.

3 Slemenda CW, Miller JZ, Hui SL, Reister TK, Johnston CC. Role of physical activity in the development of skeletal mass in children. 7 Bone Miner Res 1991;6: 1227-33.

$4 \mathrm{Kuh}$ DL, Cooper C. Physical activity at 36 years: patterns and predictors in a longitudinal study. f Epidemiol Community Health 1992;46:114-9.

5 Snow-Harter C, Bouxsein ML, Lewis BT, Carter D, Marcus R. Effects of resistance and endurance exercise on bone mineral status of young women: a randomised exercise intervention trial. $₹$ Bone Miner Res 1992;7:761-9.

6 Johnston CC, Miller JZ, Slemenda CW, Reister TK, Hui S, Christian JC, et al. Calcium supplementation and increases in bone mineral density in children. N Engl f Med 1992;327:82-7.

Drinkwater BL, Bruemner B, Chesnut $\mathrm{CH}$. Menstrual history as a determinant of current bone density in young athletes. $¥ A M A$ 1990;263:545-8.

8 Prior JC, Vigua YM, Schechter MT, Burgess AE. Spinal bone loss and ovulatory disturbances. N Engl f Med 1990;323:1221-7.

9 Wardlaw SL, Bilezikian JP. Hyperprolactinaemia and osteopenia. 7 Clin Endocrinol Metab 1992;75:690-1.

10 Schlechte J, Walkner L, Kathol M. A longitudinal analysis of premenopausal bone loss in healthy women and women with hyperprolactinaemia. J Clin Endocrinol Metab 1992;75:698-703.

11 Rigoti NA, Neer RM, Skates SJ, Herzog DB, Nussbaum SR. The clinical course of osteoporosis in anorexia nervosa: a longitudinal study of cortical bone mass. $\mathscr{f} A M A$ 1991;265:1133-8.

\title{
Rural health and health care
}

\author{
Unjustifiably neglected in Britain
}

Concern over Britain's health service has focused almost exclusively on the problems of urban areas, ${ }^{1}$ reflecting the general urban dominance in the cultural, economic, and political spheres of contemporary British society. ${ }^{2}$ This urban bias results in the belief that rural areas escape the social problems of cities, whose populations are less healthy. Other developed countries have problems associated with rurality, but in Britain the NHS is assumed to prevent them. ${ }^{1}$ Such assumptions merit further attention-if found to be incorrect then increasing the priority given to health and health care in Britain's rural population may be warranted.

Although urban districts have a higher mortality than rural ones, ${ }^{34}$ subtle variations may exist-for example, mortality in some rural districts in the north is higher than that in urban districts in the south, ${ }^{5}$ and the gradient of decreasing mortality from urban to rural areas may not persist for the remoter rural areas. ${ }^{6}$ Of the few datasets on morbidity that permit comparisons between urban and rural districts, most, such as the national morbidity study, ${ }^{7}$ point to better health in rural areas. But because such studies are rarely designed specifically for urban-rural comparison only a broad analysis is possible. However, a study in East Anglia which was designed to make this comparison used questions on self perceived illness similar to those in the general household survey and found higher prevalences of illness in rural areas. ${ }^{8}$ More recently, reanalysis of a large study of health and deprivation in the Northern region of England showed similar health patterns for matched urban and rural wards at the extremes of the socioeconomic range ${ }^{9}$ but, in contrast with Bentham's mortality study, ${ }^{6}$ a distinct health advantage for the remoter parts of the region over wards in the conurbations.

The information needed to make definitive statements on rural-urban patterns of disease is not available. Although most evidence points to greater morbidity in urban than rural areas, there is little to indicate whether this pattern holds for all rural populations in all degrees of rurality. More focused research is needed to assess how health need varies between rural and urban areas, especially for the most geographically isolated populations.

As provision of services becomes increasingly centralised ${ }^{10}$ isolated rural populations may have even less access to health care. Distance from a health facility is inversely associated with its use ${ }^{11}{ }^{12}$ : what is unclear is how much decrease in the use of health care represents unmet need. Within rural populations access may not be universally difficult and some 
groups may be affected more than others, particularly elderly people and those on low incomes, who may have the greatest need for health care. ${ }^{13}$

Inequalities of access may also result from variations in people's inclination to seek help, which is influenced by culture and geography. Perceived need, for example, has been found to relate inversely to remoteness. ${ }^{14}$ How much such barriers to access affect health outcomes in Britain is unknown. A recent study of colorectal cancer in France found that a lower proportion of the rural population than urban populations was treated in specialised health centres and that rural women were diagnosed later and had a worse prognosis than urban women. ${ }^{15}$

The costs of providing services in rural areas are usually higher because economies of scale are lacking and travel costs are higher. ${ }^{16}$ The NHS does not have a consistent policy about whether to take rurality into account when allocating resources. Scotland and Wales use a sparsity weighting when allocating resources to community health care, but the Department of Health and English health authorities do not. Rurality is taken into account throughout Britain when general practice is funded but not at all when resources for hospital services are allocated. The NHS Management Board, when reviewing the Resource Allocation Working Party formula, acknowledged that some sparsity factor may be justified in allocating resources. It noted the methodological difficulties and concluded that more research was needed. ${ }^{17}$ In addition to considering how "need" varies such research should consider how the unit costs of health care differ between rural and urban environments.

Deprivation indices, as proxies for health need, are increasingly being used to allocate resources, and it is important that such measures are validated for rural use. Their use in comparing the social problems of urban and rural areas has been criticised on the grounds that most commonly used indices have been designed for urban populations and may fail to capture the real nature of rural deprivation. ${ }^{18}$ For example, the meaning of car ownership-a variable frequently incorporated in indices-will differ in rural and urban settings. The relation between self reported morbidity and indices of deprivation has been shown to break down in non- metropolitan areas. ${ }^{19}$ Employment is declining and homelessness increasing faster in rural areas than in towns. ${ }^{20}$

The popular imagery of the rural idyll has hindered the questioning of received wisdom that life is better in the country than the city. It's time to end the comparative neglect of rural health. Senior registrar ANTONY J FRANKS Senior lecturer

Academic Unit of Public Health Medicine,

University of Leeds,

Leeds LS2 9NL

TREVOR A SHELDON Senior Research Fellow

Centre for Health Economics,

University of York,

York YO1 5DD

1 Fearn R. Rural health care: a British success or a tale of unmet need? Soc Sci Med 1987;24:263-74 2 Cater J, Jones T. Social geography - an introduction, to contemporary issues. London: Edward Amold, 1989.

3 Office of Population Censuses and Surveys. Area morality: decennial supplement 1969-73, England and Wales. London: HMSO, 1981.

4 Office of Population Censuses and Surveys. Morality and geography. A review in the mid 1980s, England and Wales. London: HMSO, 1989.

England and Wales. London: HMSO, 1989.
Chilvers C. Regional mortality 1969-73. Population Trends 1978;11:16-20.

5 Chilvers C. Regional mortality 1969-73. Population Trends 1978;11:16-20.
6 Bentham GG. Mortality in the more rural areas of England and Wales. Area 1984;16:219-26.

7 Office of Population Censuses and Surveys. Morbidity statistics from general practice. Third national study 1981-82. London: HMSO, 1989.

8 Haynes R, Bentham G. The effects of accessibility on GP consultations; out-patient attendances and in-patient admissions in Norfolk, England. Soc Sci Med 1982;16:561-9.

9 Phillimore P, Reading R. A rural advantage? Urban-rural health differences in northern England. $f$ Public Health Med 1992;14:290-9.

10 Lievesley K, Maynard W. 1991 survey of rural services. London: Rural Development Commission, 1992.

11 Parkin D. Distance as an influence on demand in general practice. $f$ Epidemiol Community Health 1979;33:96-9.

12 Haynes RM, Bentham CG. Accessibility and the ue of hospitals in rural areas. Area 1979;11:186-91. 13 Bentham CG, Haynes R. A raw deal in remoter areas? Family Practitioner Services 1986;13:84-7.

14 Bloor M, Horobin G, Taylor R, Williams R. Island health care: access to primary services in the Westerm Isles. Aberdeen: Institute of Medical Sociology, University of Aberdeen, 1978. (Occasional paper Isles. Aberdeen: Institute of Medical Sociology, University of Aberdeen, 1978. (Occasional paper No 3.)

15 Launoy G, Le Coutour X, Gignoux M, Pottier D, Dugleux G. Influence of rural environment of diagnosis, treatment, and prognosis of colorectal cancer. $\mathcal{f}$ Epidemiol Community Health 1992;46:365-7.

16 Woollett S. Counting the rural cost: the case for a rural premium. London: National Council for Voluntary Organisations, 1990.

17 Department of Health and Social Security. Report of the Resource Allocation Working Party formula: final report by the NHS Management Board. London: DHSS, 1988.

8 Knox P. Disadvantaged households and areas of deprivation: microdata for the 1981 census of Scotland. Environment and Planning A 1985;17:413-5.

19 Jessop EG. Individual morbidity and neighbourhood deprivation in a non-metropolitan area. $f$ Epidemiol Community Health 1992;46:543-6.

20 Lambert C, Jeffers S, Burton P, Bramley G. Homelessness in rural areas. Salisbury: Rural Development Commission, 1992. (Rural research series No 12.)

\title{
Home treatment for acute psychiatric disorder
}

\author{
May be better, but inpatient facilities are still needed
}

The government's plan for providing more care in the community ${ }^{1}$ has revived interest in treating patients with acute psychiatric illness at home. Potential conditions for home treatment include serious mental illness (such as schizophrenia and affective psychosis) and exacerbations of neurotic conditions.

Although some general practitioners have been doing this for years, specialist psychiatric services have moved out from their hospital bases only over the past 20 years. The first such services in Britain offered "crisis intervention"2psychotherapeutic help provided by mobile teams-but they lack systematic evaluation. ${ }^{3}$

In the United States Stein and Test established the "assertive" approach to community treatment. ${ }^{4}$ This consisted of home based assessment and treatment by multidisciplinary teams, who visited as required. Patients (half of them schizophrenic) received this form of care for 14 months, and when these patients were compared with a conventionally treated group symptoms, social functioning, satisfaction with life, employment, and drug compliance all improved and their use of psychiatric beds fell. Economic costs and the burden on family and community were comparable between the two groups. These gains were not sustained after assertive community treatment was withdrawn.

An Australian study over 12 months reported similar gains and also claimed that home treatment was $26 \%$ cheaper than conventional treatment and aftercare. ${ }^{5}$ This study was influential in changing the pattern of services in parts of Australia, where home treatment teams are now well established. A replication study was carried out in the United States, although for much longer, using staff trained by Stein and Test's team. It found, however, that gains made by patients after 30 months were not sustained at five years. ${ }^{6}$

Two recent studies have evaluated 24 hour home treatment 